Jurnal Basicedu Volume 4 Nomor 2 April 2020 Hal. 467-475

JURNAL BASICEDU

Research \& Learning in Elementary Education

https://jbasic.org/index.php/basicedu

\title{
PENERAPAN PENDEKATAN SAINTIFIK DAN MODEL TEAM GAMES TOURNAMENT TERHADAP MOTIVASI BELAJAR SISWA SEKOLAH DASAR
}

\author{
Albertus Hermawan ${ }^{1}$, Theresia Sri Rahayu ${ }^{2}$ \\ Universitas Kristen Satya Wacana, Jawa Tengah, Indonesia ${ }^{1,2}$, \\ E-mail : : albertushermawan8@gmail.com ${ }^{1}$, Theresia.rahayu@uksw.edu²
}

\begin{abstract}
Abstrak
Pembelajaran saintifik menekankan pada proses pencarian pengetahuan dari pada transfer pengetahuan, peserta didik dipandang sebagai subjek pembelajar yang perlu dilibatkan secara aktif dalam proses pembelajaran. Model Team Games Tournament melibatkan peserta didik sebagi tutor sebaya, mengandung unsur permainan yang bisa meningkatkan semangat belajar. Tujuan penelitian ini adalah untuk menguji perbedaan motivasi belajar peserta didik menggunakan model pembelajaran Saintifik dan Team Games Tournament (TGT). Jenis penelitian ini adalah penelitian eksperimen dengan menggunakan desain eksperimen semu (quasi eksperimental research). Penelitian dilaksanakan di SD Mukiran 03 dan SD Mukiran 04, Kecamatan Kaliwungu, Kabupaten Semarang pada Semester 2 tahun pelajaran 2019 - 2020. Pelaksanaan eksperimen dilakukan di kelas 4, dengan masing - masing sampel sebesar 20 peserta didik. Uji Beda dilakukan dengan metode independent t test untuk mengetahui secara komparatif perbedaan mean rata - rata bermakna antara 2 kelompok. Nilai signifikansi dari kesamaan varians yang diasumsikan dan kesamaan varians yang tidak diasumsikan memperoleh nilai < nilai alpha $(0,000<0,050)$. Hasil tersebut menunjukkan bahwa kelompok yang diberi perlakuan menggunakan model pembelajaran saintifik (SDN Mukiran 03) memiliki perbedaan signifikan dengan kelas yang diberi perlakuan menggunakan model pembelajaran team games tournament (SDN Mukiran 04).
\end{abstract}

Kata Kunci: Saintifik, Team Games Tournament, Motivasi Belajar.

\begin{abstract}
Scientific learning emphasizes the process of finding knowledge rather than transferring knowledge, students are seen as subjects of learners who need to be actively involved in the learning process. The Model Games Tournament model involves students as peer tutors, containing elements of the game that can increase learning enthusiasm. The purpose of this study was to examine differences in student learning motivation using Scientific learning models and Team Games Tournament (TGT). This type of research is experimental research using quasi experimental design (quasi experimental research). The research was conducted at Mukiran 03 Elementary School and Mukiran 04 Elementary School, Kaliwungu District, Semarang Regency in Semester 2 in the academic year 2019 - 2020. The experiment was carried out in grade 4, with each sample of 20 students. The different test was conducted using the independent $t$ test method to find out comparatively the mean difference between the mean groups. The significance value of the similarity of variance assumed and the similarity of variance that is not assumed to obtain a value <alpha value $(0,000<0.050)$. These results indicate that the groups that were treated using the scientific learning model (SDN Mukiran 03) had significant differences with the classes that were treated using the team games tournament learning model (SDN Mukiran 04).
\end{abstract}

Keywords: Scientific Learning, Team Games Tournament, Motivation to Learn

@ Jurnal Basicedu 2020

$\triangle$ Corresponding author :

Address : J1. Diponegoro No. 52 - 60 Salatiga

Email : albertushermawan8@gmail.com

ISSN 2580-3735 (Media Cetak)

Phone

ISSN 2580-1147 (Media Online) 


\section{PENDAHULUAN}

Salah satu peran guru adalah sebagai motivator. Sebagai motivator, guru harus memberikan motivasi atau rangsangan kepada peserta didik. Salah satu upaya yang dilakukan guru yaitu melalui pendekatan pembelajaran yang sesuai. Motivasi sangat menetukan tingkat keberhasilan atau gagalnya perbuatan belajar peserta didik (Hamalik, 2015). Pembelajaran saintifik tidak hanya memandang hasil belajar sebagai muara akhir, namun proses pembelajaran dipandang sangat penting. Pendekatan saintifik menekankan pada keterampilan proses. Menekankan pada proses pencarian pengetahuan dari pada transfer pengetahuan, peserta didik dipandang sebagai subjek pembelajar yang perlu dilibatkan secara aktif dalam proses pembelajaran.

Pembelajaran kooperatif tipe TGT (Team

Games Tournament) menggunakan sistem pengelompokan atau tim kecil, yaitu empat sampai enam orang yang mempunyai latar belakang kemampuan akademik, jenis kelamin, ras, atau suku yang berbeda. Model ini melibatkan peserta didik sebagi tutor sebaya, mengandung unsur permainan yang bisa menggairahkan semangat belajar. Tujuan penelitian ini adalah untuk mengetahui perbedaan motivasi belajar menggunakan model pembelajaran Saintifik dan Team Games Tournament (TGT) pada siswa di SDN Mukiran 03 dan SDN Mukiran 04 semester 2 tahun pelajaran 2019 - 2020.

Manfaat penelitian sebagai bahan pertimbangan pemilihan metode pembelajaran terutama dalam pembelajaran tematik Memberikan masukan kepada sekolah tentang penerapan metode pembelajaran TGT dan Pendekatan Saintifik agar mutu dan kualitas sekolah dapat meningkat. Hasil penelitian ini dapat dimanfaatkan sebagai salah satu usaha memperbanyak serta memperdalam pengetahuan penulis yang lain tentang efektivitas pembelajaran TGT dan Pendekatan Saintifik terhadap motivasi belajar siswa.

Pendekatan saintifik adalah pembelajaran yang dirancang sedemikian rupa agar peserta didik dapat mengorganisasikan suatu konsep, hukum ataupun prinsip (Daryanto, 2012). Pembelajaran pendekatan scientific adalah "pembelajaran yang memberikan kesempatan siswa untuk aktif dalam membangun suatu konsep, hukum atau prinsip dengan melibatkan keterampilan proses dalam kegiatan pembelajaran" (Kurniasih \& Sani, 2014). Menurut (Rusman, 2015) pendekatan saintifik menuntut siswa untuk lebih aktif, kreatif serta mampu memiliki keterampilan ilmiah. Berdasarkan uraian para ahli di atas, dapat disimpulkan bahwa pendekatan saintifik adalah proses pembelajaran yang memberikan kesempatan kepada siswa untuk terampil membangun suatu konsep, hukum atau prinsip dengan menggunakan berbagai sumber belajar.

Hosnan (2014) memaparkan langkahlangkah pembelajaran dengan pendekatan scientific adalah sebagai berikut:

1. Mengamati (Observing)

Dalam tahap observasi mengedepankan pengamatan langsung pada objek yang akan dipelajari sehingga peserta didik mendapatkan fakta berbentuk data yang objektif sehingga peserta didik mendapatkan fakta berbentuk data yang objektif yang kemudian dianalisis sesuatu tingkat perkembangan peserta didik.

\section{Menanya (Questioning)}

Dalam tahap menanya, kegiatan yang dilakukan yaitu mengajukan pertanyaan mengenai informasi untuk mendapatkan informasi tentang apa yang diamati.

\section{Mengeksplorasi}


Kegiatan ini dilakukan dengan mencari atau menggali dan mengumpulkan informasi dari berbagai sumber melalui berbagai cara.

\section{Mengasosiasi (Associating)}

Istilah menalar (associating) dalam krangka proses pembelajaran dengan pendekatan saintifik yang dianut dalam kurikulum 2013 untuk menggambarkan bahwa guru dan peserta didik merupakan pelaku aktif. Titik tekannya tentu dalam banyak hal dan situasi siswa harus lebih aktif daripada guru.

\section{Mengkomunikasikan}

Pada tahap ini, diharapkan siswa dapat mengkounikasikan hasil pekerjaan yang telah disusun baik secara bersama-sama dalam kelompok atau scara individu dari hasil kesimpulan yang telah dibuat bersama (Hosnan, 2014).

Pembelajaran kooperatif model TGT adalah salah satu tipe atau model pembelajaran kooperatif yang mudah diterapkan karena melibatkan peran aktif peserta didik tanpa ada perbedaan status dan melibatkan peran peserta didik sebagai tutor sebaya dalam kelompok, serta pembelajarannya juga mengandung unsur permainan dan penguatan (Aris, 2013). Aktivitas belajar dengan permainan yang dirancang dalam pembelajaran kooperatif tipe TGT memungkinkan peserta didik dapat belajar lebih rileks di samping menumbuhkan tanggung jawab, kejujuran, kerjasama, persaingan sehat dan keterlibatan belajar (Fathurrohman, 2015). Slavin (2010:163) TGT adalah model pembelajaran kooperatif menggunakan turnamen akademik dan menggunakan kuis-kuis, dimana para siswa berlomba sebagai wakil tim mereka dengan anggota tim lain yang kinerja akademik sebelum setara seperti mereka (Slavin, 2005).

Langkah-langkah pembelajaran TGT secara runtut, yaitu :
1. Peserta didik ditempatkan dalam tim belajar beranggotakan empat orang yang merupakan campuran menurut tingkat prestasi, jenis kelamin, dan suku.

2. Guru menyiapkan pelajaran, dan kemudian peserta didik bekerja didalam tim mereka untuk memastikan bahwa seluruh anggota tim telah menguasai pelajaran tersebut.

3. Seluruh peserta didik dikenai kuis, pada waktu kuis ini mereka tidak dapat saling membantu (Trianto, 2009).

Indikator motivasi belajar menurut (Uno, 2016) dapat diklasifikasikan sebagai berikut:

1. Adanya hasrat dan keinginan untuk berhasil,

2. Adanya dorongan dan kebutuhan dalam belajar,

3. Adanya harapan atau cita-cita pada masa depan,

4. Adanya penghargaan dalam belajar,

5. Adanya kegiatan yang menarik dalam situasi belajar,

6. Adanya lingkungan belajar yang kondusif.

Cara terbaik untuk memberikan motivasi kepada anak usia SD dapat dilakukan dengan mengenalkan permainan edukasi yang menyenangkan (Supriadi, 2017). Hasil belajar akan lebih optimal apabila ada motivasi. Tiga fungsi motivasi, yakni:

1. Mendorong manusia untuk berbuat. Motivasi di sini diartikan sebagai penggerak dari setiap kegiatan yang akan dilakukan manusia.

2. Menentukan arah perbuatan, yakni ke arah tujuan yang hendak dicapai.

3. Menyeleksi perbuatan, yakni menentukan perbuatan-perbuatan apa yang harus dikerjakan yang serasi guna mencapai tujuan, dengan menyisihkan perbuatan-perbuatan yang tidak bermanfaat bagi tujuan tersebut (Sardiman, 2014).

Menurut (Purwanto, 2013) tujuan motivasi adalah untuk menggerakkan atau menggugah 
$470 \quad$ Penerapan pendekatan saintifik dan model TGT terhadap motivasi belajar siswa sekolah dasar Albertus Hermawan, Theresia Sri Rahayu

seseorang agar secara sadar dan sengaja timbul keinginan dan kemampuannya untuk melakukan sesuatu sehingga dapat memperoleh hasil dan mencapai tujuan yang diinginkan

\section{METODE}

Jenis penelitian ini adalah penelitian eksperimen dengan menggunakan desain eksperimen semu (quasi eksperimental research). Desain eksperimen yang berupa penelitian kuasi eksperimen diartikan sebagai penelitian yang mendekati eksperimen atau eksperimen semu. Penelitian ini bertujuan untuk mengungkapkan hubungan sebab akibat dengan cara melibatkan kelompok kontrol disamping kelompok eksperimen, namun pemilahan kedua kelompok (kelompok eksperimen dan kelompok kontrol) tidak dengan teknik random. Oleh karena itu rancangan ini relatif lebih cermat dalam mengungkapkan hubungan sebab akibat dan memiliki karakteristik penelitian sebagai berikut:

1. Masalah pembelajaran dalam merancang desai pembelajaran tematik.

2. Menggunakan subjek penelitian siswa kelas IV SD.

3. Mengendalikan variabel Model Pembelajaran Saintifik Team Games Tournament (S-TGT).

Tabel 1. Desain Eksperimen Penelitian

\begin{tabular}{lll}
\hline $\mathrm{O}_{1}$ & $\mathrm{X}$ & $\mathrm{O}_{2}$ \\
\hline $\mathrm{O}_{3}$ & & $\mathrm{O}_{4}$
\end{tabular}

Keterangan:

$\mathrm{X}$ : Perlakuan menggunakan MP MM

$\mathrm{O}_{1}$ : Pengukuran pretest kelompok eksperimen 1

$\mathrm{O}_{2}$ : Pengukuran posttest kelompok eksperimen 1

$\mathrm{O}_{3}$ : Pengukuran pretest kelompok eksperimen 2

$\mathrm{O}_{4}$ : Pengukuran posttest kelompok eksperimen 2

Pada awal penelitian dilakukan pretest kelompok eksperimen untuk mengetahui normalitas dan homogenitas. Populasi dan sampel dalam penelitian ini adalah siswa kelas IV SDN Mukiran 03 dan SDN Mukiran 04. Teknik pengambilan sampel menggunakan teknik purposive stratified proportionate sampling yakni sampel yang diambil berdasarkan tujuan, menentukan jenjang kelas yakni kelas 4 (stratified), dan mengambil sampel secara proposional yaitu 20 siswa di masing - masing dalam kelas (proportionate).

Teknik pengumpulan data yang digunakan adalah teknik observasi. Instrumen menggunakan kuesioner amatan dengan indikator empirik yang dinilai berdasarkan masing - masing subjek penelitian. Teknik analisis data yang digunakan dalam penelitian ini adalah uji paired sample t test dengan komparatif atau uji perbandingan hasil.

\section{HASIL DAN PEMBAHASAN}

Pre test dilakukan sebagai kegiatan untuk menguji tingkat pengetahuan siswa terhadap materi Tema Daerah Tempat Tinggalku Subtema Bangga Terhadap Daerah Tempat Tinggalku pada Kurikulum 2013. Materi soal yang diujikan meliputi mata pelajaran: Ilmu Pengetahuan Alam (IPA), Ilmu Pengetahuan Sosial (IPS), Matematika dan Bahasa Indonesia. Hasil nilai Pre Test siswa dapat dilihat pada Tabel 2 berikut:

Tabel 2. Hasil Nilai Uji Kemampuan Awal

\begin{tabular}{|c|c|c|c|}
\hline & & $\begin{array}{c}\text { Kelas } \\
\text { Eksperimen } \\
1\end{array}$ & $\begin{array}{c}\text { Kelas } \\
\text { Eksperimen } \\
2\end{array}$ \\
\hline \multirow[t]{2}{*}{$\mathrm{N}$} & Valid & 20 & 20 \\
\hline & Missing & 0 & 0 \\
\hline \multicolumn{2}{|l|}{ Mean } & 63,75 & 60,83 \\
\hline \multicolumn{2}{|l|}{ Median } & 62,50 & 60,00 \\
\hline \multicolumn{2}{|l|}{ Mode } & $60^{a}$ & 60 \\
\hline \multicolumn{2}{|l|}{ Std. Deviation } & 7,424 & 8,483 \\
\hline \multicolumn{2}{|l|}{ Variance } & 55,114 & 71,970 \\
\hline \multicolumn{2}{|l|}{ Minimum } & 50 & 45 \\
\hline \multicolumn{2}{|l|}{ Maximum } & 75 & 75 \\
\hline \multicolumn{2}{|l|}{ Sum } & 765 & 730 \\
\hline \multirow[t]{3}{*}{ Percentiles } & 25 & 60,00 & 56,25 \\
\hline & 50 & 62,50 & 60,00 \\
\hline & 75 & 70,00 & 68,75 \\
\hline
\end{tabular}

a. Multiple modes exist. The smallest value is shown

Berdasarkan tabel 2 nilai rata-rata kelas eksperimen $1>$ kelas eksperimen 2 (63,75> 60,83). Nilai rata-rata subjek penelitian berada 
471 Penerapan pendekatan saintifik dan model TGT terhadap motivasi belajar siswa sekolah dasar Albertus Hermawan, Theresia Sri Rahayu

dalam kategori rendah $(<70)$, hal ini dikarenakan penerapan Kurikulum 2013 pada satu bidang subtema mencakup empat hingga enam mata pelajaran, sehingga siswa masih perlu penyesuaian. Setelah didapatkan nilai hasil pre test dilakukan uji normalitas untuk mengetahui bagaimana sebaran data nilai hasil uji kemampuan awal. Uji kemampuan akhir dilakukan dengan menganalisis seluruh aspek variabel motivasi belajar pada kelas eksperimen 1 (SDN Mukiran 03) dan kelas eksperimen 2 (SDN Mukiran 04). Distribusi hasil analisis empat dimensi motivasi belajar siswa setelah dilakukan intervensi belajar menggunakan model Saintifik diperoleh hasil sebagai berikut:

Tabel 3. Distribusi Statistik Kelas Eksperimen 1

\begin{tabular}{|c|c|}
\hline 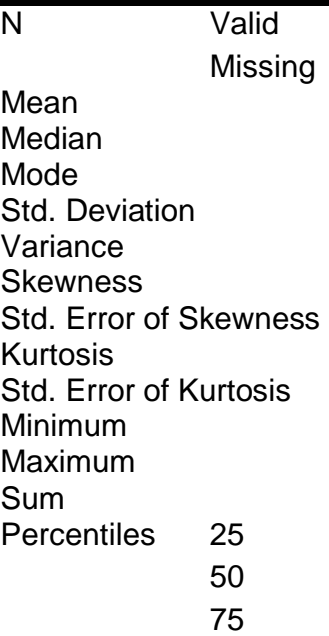 & $\begin{array}{r}600 \\
0 \\
3,69 \\
4,00 \\
4 \\
, 726 \\
, 527 \\
-, 255 \\
, 100 \\
, 049 \\
, 199 \\
1 \\
5 \\
2211 \\
3,00 \\
4,00 \\
4,00\end{array}$ \\
\hline
\end{tabular}

Berdasarkan data pada tabel 3 diperoleh nilai rata - rata motivasi belajar siswa di SDN Mukiran 03 menggunakan model pembelajaran saintifik yaitu 3,69 (masuk kategori tinggi). Grafik histogram gambaran motivasi belajar siswa SDN Mukiran 03 dapat dilihat pada Gambar 1 berikut:

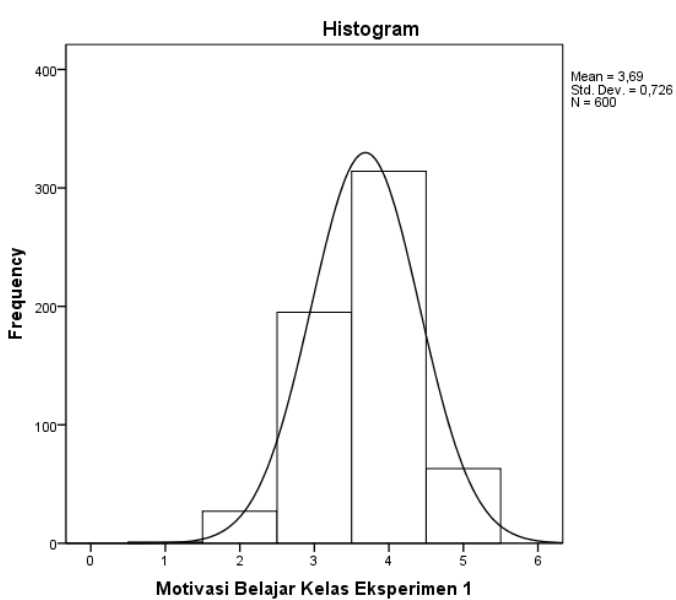

\section{Gambar 1. Grafik Motivasi Belajar Siswa Menggunakan Model Saintifik}

Setelah kategori tinggi, perolehan intervensi motivasi belajar menggunakan model saintifik berada pada nilai tengah yaitu sedang. Hal tersebut dapat mengidikasikan bahwa masih terdapat siswa yang masih belum memahami dan mampu mengikuti model pembelajaran secara maksimal.

Tabel 4. Distribusi Statistik Kelas Eksperimen 2

\begin{tabular}{|c|c|}
\hline 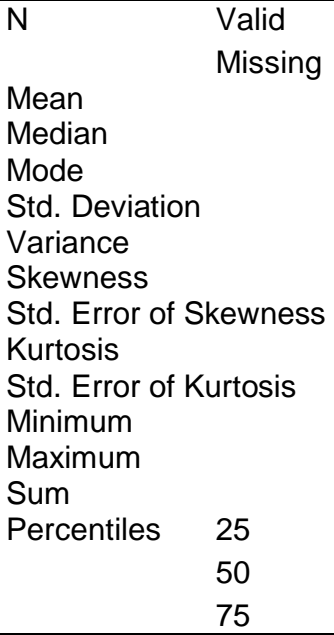 & $\begin{array}{r}600 \\
0 \\
4,00 \\
4,00 \\
4 \\
, 761 \\
, 579 \\
-, 909 \\
, 100 \\
1,856 \\
, 199 \\
1 \\
5 \\
2399 \\
4,00 \\
4,00 \\
4,00\end{array}$ \\
\hline
\end{tabular}

Berdasarkan data pada tabel 4 diperoleh nilai rata - rata motivasi belajar siswa di SDN Mukiran 04 menggunakan model pembelajaran saintifik yaitu 4,00 (masuk kategori tinggi). Grafik histogram gambaran motivasi belajar siswa SDN Mukiran 04 dapat dilihat pada Gambar 2 berikut: 


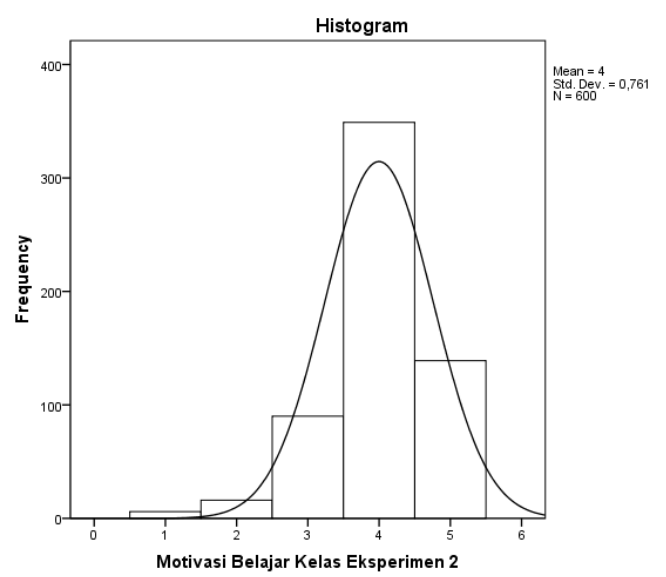

Gambar 2. Grafik Motivasi Belajar Siswa Menggunakan Model Team Games Tournament

Setelah kategori tinggi, perolehan intervensi motivasi belajar menggunakan model saintifik berada pada nilai tinggi. Hal tersebut dapat mengidikasikan bahwa siswa mulai mampu mengikuti model pembelajaran secara maksimal.

Tabel 5. One Sample Kolmogorov-Smirnov Test

\begin{tabular}{|c|c|c|c|}
\hline & & $\begin{array}{c}\text { Kelas } \\
\text { Eksperimen } \\
1\end{array}$ & $\begin{array}{c}\text { Kelas } \\
\text { Eksperimen } \\
2\end{array}$ \\
\hline $\mathrm{N}$ & & 20 & 20 \\
\hline Normal & Mean & 110,55 & 119,95 \\
\hline$\underset{\mathrm{a}, \mathrm{b}}{\text { Parameters }}$ & $\begin{array}{l}\text { Std. } \\
\text { Deviation }\end{array}$ & 5,135 & 6,362 \\
\hline Most & Absolute & ,143 & ,084 \\
\hline Extreme & Positive & , 143 & ,084 \\
\hline Differences & Negative &,- 101 &,- 075 \\
\hline Kolmogorov-S & Smirnov Z & ,638 & ,378 \\
\hline Asymp. Sig. ( & 2-tailed) & ,810 & ,999 \\
\hline
\end{tabular}

Pendekatan asumsi yang digunakan untuk menguji normalitas data adalah nilai $\alpha=$ 0,05. Jika nilai signifikansi normalitas kurang dari nilai $\alpha$ maka dapat dikatakan data tidak normal (non parametrik) Berdasarkan hasil data pada tabel 5, nilai Asymp. Sig. (2-tailed) kelas kontrol > nilai $\alpha \quad(0,810>0,05)$, maka dapat disimpulkan bahwa distribusi data kelas eksperimen 1 normal (parametrik). nilai Asymp. Sig. (2-tailed) kelas eksperimen $2>$ nilai $\alpha \quad(0,999>0,05)$, maka dapat disimpulkan bahwa distribusi data kelas eksperimen 2 normal (parametrik).

Uji Homogenitas hasil akhir penelitian motivasi siswa menggunakan model saintifik pada SDN Mukiran 03 dan model Team Games Tournament pada SDN Mukiran 04 bertujuan untuk mengetahui apakah data dari seluruh populasi memiliki tingkat varians yang sama atau tidak.

Tabel 6. Test of Homogeneity of Variance

\begin{tabular}{|c|c|c|c|}
\hline Levene Statistic & $\mathrm{df} 1$ & $\mathrm{df} 2$ & Sig. \\
\hline ,937 & 1 & 38 & ,339 \\
\hline
\end{tabular}

Berdasarkan hasil analisis homogenitas menggunakan Levene Statistic diperoleh nilai signifikansi > dari nilai alpha $(0,339>0,05)$. Hasil tersebut memberikan penjelasan bahwa kedua kelas memiliki tingkat homogenitas motivasi belajar yang sama.

Uji Beda dilakukan dengan metode independent $t$ test untuk mengetahui secara komparatif perbedaan mean rata - rata bermakna antara 2 kelompok yaitu kelompok yang diberi perlakuan menggunakan model pembelajaran saintifik dan kelompok yang diberi perlakuan menggunakan model pembelajaran team games tournament.

Tabel 6. Independent Samples Test Akhir Perbedaan Motivasi Belajar

\begin{tabular}{|ll|c|r|r|}
\hline \multirow{2}{*}{} & & \multicolumn{3}{|c|}{ t-test for Equality of Means } \\
\cline { 2 - 5 } & $\mathrm{t}$ & $\mathrm{df}$ & $\begin{array}{c}\text { Sig. } \\
\text { (2-tailed) }\end{array}$ \\
\hline $\begin{array}{l}\text { Motivasi } \\
\text { Belajar }\end{array}$ & $\begin{array}{l}\text { Equal variances } \\
\text { assumed } \\
\text { Equal variances } \\
\text { not assumed }\end{array}$ & $-5,142$ & 38 &, 000 \\
\hline
\end{tabular}


473 Penerapan pendekatan saintifik dan model TGT terhadap motivasi belajar siswa sekolah dasar Albertus Hermawan, Theresia Sri Rahayu

Nilai signifikansi dari kesamaan varians yang diasumsikan dan kesamaan varians yang tidak diasumsikan memperoleh nilai < nilai alpha $(0,000<0,050)$. Hasil tersebut menunjukkan bahwa kelompok yang diberi perlakuan menggunakan model pembelajaran saintifik (SDN Mukiran 03) memiliki perbedaan signifikan dengan kelas yang diberi perlakuan menggunakan model pembelajaran team games tournament (SDN Mukiran 04).

Salah satu upaya guru untuk memberikan pendekatan yang sesuai dengan keadaan kelas adalah dengan model pembelajaran yang tepat. Tujuan dari penerapan suatu model pembelajaran adalah untuk meningkatkan motivasi belajar siswa. Jika motivasi belajar siswa dapat meningkat maka diharapkan hasil belajar dapat dimaksimalkan. Pada aspek tersebut, guru sebagai motivator utama dalam menghasilkan output belajar yang maksimal dapat memberikan beberapa eksperimen model. Pada penelitian ini model eksperimen yang diterapkan yaitu model pembelajaran saintifik (diterapkan pada siswa SDN Mukiran 03) dan pembelajaran team games torunament (diterapkan pada siswa SDN Mukiran 04). Penelitian dilakukan terhadap 20 siswa masing - masing kelompok eksperimen.

Penelitian dilakukan dengan tiga tahap: Tahap pertama dilakukan dengan melakukan uji coba try out instrument penelitian motivasi belajar kepada 32 siswa kelas V. Hasil diperoleh bahwa keseluruhan item pernyataan valid dan tingkat reliabilitas masing - masing aspek motivasi belajar diperoleh reliable (> 0,06). Tahap uji kemampuan awal dilakukan dengan menggunakan instrument soal formatif. Kelas eksperimen 1 diperoleh nilai rata - rata tanpa menggunakan model pembelajaran yaitu 63,75 . Kelas eksperimen 2 diperoleh nilai rata - rata tanpa menggunakan model pembelajaran yaitu 60,83 . Tahap kedua pada bagian pre test dialakukan uji normalitas data nilai kognifif. Uji normalitas hasil pre test menggunakan metode Kolmogorov smirnov diperoleh kedua kelas eksperimen memiliki tingkat distribusi data yang normal $(>0,05)$.

Kedua hasil tersebut kemudian dilakukan uji homogentias menggunakan Levene Statistic. Uji homogenitas dilakukan untuk memastikan bahwa kedua kelas eksperimen memiliki tingkat karakteristik pengetahuan dan kemampuan belajar yang sama. Tahap akhir pada penelitian pre test dilakukan uji beda menggunakan independent $\mathrm{t}$ - test pada nilai hasil belajar kognifif. Hasil equality of means dari kedua kelas eksperimen diperoleh tidak terdapat perbedaan signifikan $(>0,05)$.

Pelaksanaan penelitian dilakukan masing - masing pada SDN Mukiran 03 dan SDN Mukiran 04. Pelaksanaan penelitian dilakukan secara time series yaitu dilakukan pada waktu berbeda menggunakan dua model yang berbeda. SDN Mukiran 03 dilakukan intervensi menggunakan model pembelajaran Saintifik sesuai dengan langkah - langkah yang telah dikemukakan pada metode pelaksanaan. SDN Mukiran 04 dilakukan intervensi menggunakan model pembelajaran Team Games Torunament sesuai dengan langkah - langkah yang telah dikemukakan pada metode pelaksanaan. Tahap observasi dilakukan dengan memberikan masing masing siswa distribusi instrument penelitian 
474 Penerapan pendekatan saintifik dan model TGT terhadap motivasi belajar siswa sekolah dasar Albertus Hermawan, Theresia Sri Rahayu

motivasi yang terdiri dari aspek: keinginan untuk berhasil, kebutuhan dalam belajar, harapan di masa depan, penghargaan dalam belajar dan situasi belajar.

Distrubusi statistik perlakuan yang diberikan kepada siswa mengguankan model saintifik diperoleh nilai 3,69 (masuk pada kategori tinggi) dan nilai distribusi rata - rata pada model team games tournament diperoleh nilai 4. Secara analisis univariat tingkat motivasi siswa menggunakan model team games tournament lebih tinggi dibandingkan dengan tingkat motivasi siswa menggunakan model saintifik. Hasil uji asumsi hipotesis penelitian diperoleh bahwa terdapat perbedaan signifikan antara penggunaan model pembelajaran saintifik dan model pembelajaran team games tournament.

Hasil Penelitian ini dapat menginterpretasikan penelitian sebelumnya dari (Desi Indriyani, Desyandri, Yanti Fitria, 2019) yang menyatakan bahwa penerapan pemahaman konseptual pada mahasiswa PGSD dapat dilakukan dengan pendekatan saintifik. Pada penelitian ini pendekatan saintifik dipraktikan dengan menerapkan pada siswa secara langsung. Hasil penelitian juga melengkapi penelitian (Hilda et al., 2020) bahwa motivasi belajar dapat ditingkatkan dengan pendekatan contextual teaching and learning. Pada penelitian ini motivasi belajar dapat ditingkatkan menggunakan model pembelajaran team games tournament.

\section{SIMPULAN}

Penelitian dilaksanakan di SD Mukiran

03 dan SD Mukiran 04, Kecamatan Kaliwungu, Kabupaten Semarang pada
Semester 2 tahun pelajaran 2019 - 2020 . Pelaksanaan eksperimen dilakukan di kelas 4, dengan masing - masing sampel sebesar 20 peserta didik. Dari jumlah populasi tersebut kemudian dibagi menjadi 2 kelas sampel yaitu kelas eksperimen 1 dan kelas eksperimen 2 . Uji Beda dilakukan dengan metode independent $t$ test untuk mengetahui secara komparatif perbedaan mean rata - rata bermakna antara 2 kelompok yaitu kelompok yang diberi perlakuan menggunakan model pembelajaran saintifik dan kelompok yang diberi perlakuan menggunakan model pembelajaran team games tournament. Hasil penelitian menunjukkan bahwa kelompok yang diberi perlakuan menggunakan model pembelajaran saintifik (SDN Mukiran 03) memiliki perbedaan signifikan dengan kelas yang diberi perlakuan menggunakan model pembelajaran team games tournament (SDN Mukiran 04).

\section{DAFTAR PUSTAKA}

Aris, S. (2013). 68 Model Pembelajaran Inovatif dalam Kurikulum 2013 (Vol. 53, Issue 9). Ar-Ruzz Media. https://doi.org/10.1017/CBO9781107415324. 004

Daryanto. (2012). Model Pembelajaran Inovatif. Gava Media.

Desi Indriyani, Desyandri, Yanti Fitria, I. (2019). Analisis Pemahaman Konseptual Mahasiswa PGSD pada Mata Kuliah Perencanaan Menggunakan Pendekatan Saintifik. Jurnal Basicedu, 3(2), 524-532.

Fathurrohman, M. (2015). Model - Model Pembelajaran Inovatif. Ar-Ruzz Media.

Hamalik, O. (2015). Kurikulum dan Pembelajaran. Bumi Aksara.

Hilda, Fitria, Y., \& Zikri, A. (2020). Penerapan Pendekatan Contextual Teaching and Learning pada Pembelajaran IPA untuk Meningkatkan Hasil Belajar dan Motivasi Belajar Siswa Sekolah Dasar. Jurnal Basicedu, 4(1), 149-157. 
475 Penerapan pendekatan saintifik dan model TGT terhadap motivasi belajar siswa sekolah dasar Albertus Hermawan, Theresia Sri Rahayu

Hosnan. (2014). Pendekatan Saintifik dan Kontekstual dalam Pembelajaran Abad 21. Ghalia Indonesia.

Kurniasih, I., \& Sani, B. (2014). Implementasi Kurikulum 2013 Konsep \&. Penerapan. Kata Pena.

Purwanto. (2013). Evaluasi Hasil Belajar. Pustaka Pelajar.

Rusman. (2015). Pembelajaran Tematik Terpadu Teori, Praktik dan Penilaian. Rajawali Pers.

Sardiman. (2014). Interaksi dan Motivasi Belajar Mengajar. Rajawali Pers.

Slavin. (2005). Cooperative Learning Teori, Riset dan Praktik. Nusa Media.

Supriadi. (2017). Komunikasi Pembelajaran. Remaja Rosdakarya.

Trianto. (2009). Mengembangkan Materi Pembelajaran Tematik. Prestasi Pustakarya.

Uno, H. (2016). Model Pembelajaran Menciptakan Proses Belajar Mengajar yang Kreatif dan Efektif. Bumi Aksara. 